\title{
Application of Gas Chromatography High-Resolution Mass Spectrometry to the Determination of Trace Monobromopolychlorodibenzo- $p$-Dioxins in Environmental Samples
}

\author{
Lee Q. Huang and Anthony Paiva \\ Department of Analytical Chemistry, The Connecticut Agricultural Experiment Station, New Haven, \\ Connecticut, USA \\ Huayi Tong*, Steve J. Monson, and Michael L. Gross \\ Midwest Center for Mass Spectrometry, Department of Chemistry. University of Nebraska, Lincoln, \\ Nebraska, USA
}

\begin{abstract}
A capillary column gas chromatographic/high resolution mass spectrometric method was developed for the determination of monobromopolychlorodibenzo- $p$-dioxins (BPCDDs) in environmental samples. The mass spectrometer was operated at high resolution $(>10,000)$ in the selected ion monitoring mode with magnet switching among tetra through octa groups to achieve low or subpicogram detection limits. Standard BPCDDs (tetracongener through octacongener groups) were utilized to measure accurately the mass spectrometric relative response factors for these compounds, and linear calibrations were achieved by using these standard compounds at different concentrations. The method detection limit is low or sub-parts-per-trillion levels for BPCDDs, the accuracy better than $80 \%$ and the precision better than $\pm 10 \%$. Quantification of $B P C D D s$ and preliminary identification of some specific BPCDD isomers in fly ash samples are also reported. (] Am Soc Mass Spectrom 1992, 3, 248-259)
\end{abstract}

$\mathrm{T}$ The analysis of environmental and biological samples for polychlorinated dibenzo-p-dioxins (PCDDs) has received considerable public and scientific attention during the past several decades [1-3] because these compounds are highly toxic [4, 5]. Recent findings of polybrominated dibenzo- $p$-dioxins (PBDDs) in some samples [6-12] have also raised concern about their environmental impact. Brominated dioxins seem to have similar or even higher toxicity than that of PCDDs, at least for some isomers (e.g., 2,3,7,8- $\mathrm{Br}_{4} \mathrm{DD}$ was shown to have higher activity than $2,3,7,8-\mathrm{Cl}_{4} \mathrm{DD}$ at inducing 7-ethyoxyresorufin deethylase and aryl hydrocarbon hydroxylase $[13,14]$ ). At the present time, very little is known about mixed bromo/chloro dioxins such as monobromopolychlorodibenzo-p-dioxins (BPCDDs), although structural considerations and biological activity of these compounds

*Present address: Ciba-Geigy Corp., Analytical Research, 444 Saw *Present address: Ciba-Geigy Corp., Ana

Mill River Road, Ardsley, NY 10502-2699.
Address reprint requests to Lee Q. Huang, The Connecticut AgriAddress reprint requests to Lee Q. Huang, The Connecticut Agri-
cultural Experiment Station, 123 Huntington Street, New Haven, CT 06511 . indicate that their toxicity is similar to that of PCDDs and PBDDs $[15,16]$.

The analysis for BPCDDs is of great importance, not only for understanding the distribution of these potential hazards in the environment but also for providing information regarding the formation mechanism of dioxins. In mechanistic studies, the bromine atom may be viewed as a "label" [16]. Some early studies showed that BPCDDs can indeed be formed under laboratory conditions [6, 17-19]. Others have reported finding BPCDDs in residues from chemical waste incinerators [15] and in fly ash from municipal waste incinerators $[8-10,20,21]$. To date, however, only qualitative or semiquantitative information about BPCDDs in the environment is available owing to the lack of sensitive assays and standard compounds.

Mass spectrometry has been the leading technique used in dioxin analysis, and mass spectrometric methods for the analysis of PCDDs are well established $[22,23]$. Quantitative analysis of BPCDDs is, however, much more difficult than the analysis of PCDDs because: (1) very few standard compounds of BPCDDs 
are currently available for calibration and quantification; (2) the levels of BPCDDs are a factor of $\sim 30$ times lower than those of PCDD counterparts as estimated in early studies $[6,16]$; (3) there are many more possible isomers of BPCDDs than those of PCDDs (there are 198 isomeric BPCDD compounds for tetrahalogen through octahalogen substitution and 70 isomeric tetra-substituted compounds whereas there are 49 PCDD isomers of tetrasubstitution through octasubstitution and 22 isomeric tcdds); (4) mass spectrometric responses of BPCDDs are a factor of 2-5 times lower than that of PCDDs [16], and this demands higher sensitivity for the analysis of BPCDDs; (5) the analysis of BPCDDs is more complicated because large quantities of chloro analogues are usually present. Under such circumstances, the analytical method must have an extremely high sensitivity and specificity for the quantitative determination of BPCDDs.

Capillary column gas chromatography (GC) in combination with low-resolution mass spectrometry (LRMS), operated in the electron ionization (EI) mode was utilized for the analysis of BPCDDs $[9,15]$, but all congeners of BPCDDs could not be detected because of the low sensitivity and specificity of LRMS. High resolution (HR)GC/LRMS, in the negative chemical ionization (NCI) mode, provided better sensitivity and specificity when monitoring the $\mathrm{Br}$ anions at $\mathrm{m} / \mathrm{z} 79$ and 81 for BPCDDs [8-10]. This method, however, can be used only for screening samples for BPCDDs because positive identification cannot be based solely on the ions of $m / z 79$ and 81. Furthermore, the NCI technique is not ideal for quantitative analysis because mass spectrometric response factors vary with dioxin isomers and depend on many parameters such as reagent gas pressure, source temperature, and trace impurities in the reagent gas [24-26]. In general, the absolute instrumental sensitivity of LRMS (quadrupole mass spectrometer) is two to three orders of magnitude poorer than that achievable by a modern high resolution mass spectrometer (magnetic sector instruments). Also, on the basis of preliminary results, we suggest that the capillary column GC/HRMS in the EI mode is the method of choice to meet these challenges [16].

In this study, a quantitative method was developed for the determination of BPCDDs by using capillary column GC/HRMS. The protocol is similar to the methods for PCDDs and ${ }^{13} \mathrm{C}$-labeled PCDD compounds serve as internal standards for the determination of BPCDDs. By using synthesized BPCDD standard compounds, we were able to measure accurately the relative response factors (RRFs) of BPCDDs to their ${ }^{13} \mathrm{C}$-labeled PCDD internal standards for the furst time. Modern high resolution mass spectrometers can routinely detect dioxins in the femtogram range, which makes it possible to determine BPCDDs at low or sub-parts-per-trillion (pptr) levels. Because two of the most efficient GC columns for dioxin analysis, 60-m-long DB-5 and DB-DIOXIN, were employed in combination with some BPCDD standards, preliminary identification of some BPCDD isomers detected in fly ash samples could also be accomplished.

\section{Experimental}

\section{Reagents and Standard Compounds}

All solvents were pesticide grade (J. T. Baker, Phillipsburg, NJ) or HPLC grade (Fisher Scientific, Fairlawn, NJ) and were used without further purification.

Table 1. Concentrations of BPCDDs and internal standards in calibration solutions (CS)

\begin{tabular}{|c|c|c|c|c|c|c|}
\hline & \multicolumn{6}{|c|}{ Concentration $(p q / \mu)$} \\
\hline & $\operatorname{CS1}$ & CS2 & $\operatorname{cs} 3$ & CS4 & CS5 & CS6 \\
\hline \multicolumn{7}{|l|}{ Uniabeled analytes } \\
\hline $2-\mathrm{Br}-3,7,8-\mathrm{Cl}_{3} \mathrm{DD}$ & 0.5 & 2 & 10 & 50 & 100 & 200 \\
\hline $2-\mathrm{Br}-1,3,7,8-\mathrm{Cl}_{4} \mathrm{DD}$ & 2.5 & 10 & 50 & 250 & 500 & 1000 \\
\hline $2-\mathrm{Br}-3,6,7,8,9-\mathrm{Cl}{ }_{5} \mathrm{DD}$ & 2.5 & 10 & 50 & 250 & 500 & 1000 \\
\hline $1-\mathrm{Br}-2,3,6,7,8,9-\mathrm{Cl}_{6} \mathrm{DD}$ & 2.5 & 10 & 50 & 250 & 500 & 1000 \\
\hline $1-\mathrm{Br}-2,3,4,6,7,8,9-\mathrm{Cl}_{7} \mathrm{DD}$ & 5.0 & 20 & 100 & 500 & 1000 & 2000 \\
\hline \multicolumn{7}{|l|}{ Internal standards } \\
\hline${ }^{13} \mathrm{C}_{12}-1-\mathrm{Br}-2,3,7,8-\mathrm{Cl}_{3} \mathrm{DD}$ & 10 & 10 & 10 & 10 & 10 & 10 \\
\hline${ }^{13} \mathrm{C}_{12}-2,3,7,8-\mathrm{Cl}_{4} \mathrm{DD}$ & 10 & 10 & 10 & 10 & 10 & 10 \\
\hline${ }^{13} \mathrm{C}_{12}-1,2,3,7,8-\mathrm{Cl}_{5} \mathrm{DD}$ & 10 & 10 & 10 & 10 & 10 & 10 \\
\hline${ }^{13} \mathrm{C}_{12}-1,2,3,6,7,8-\mathrm{Cl}_{6} \mathrm{DD}$ & 25 & 25 & 25 & 25 & 25 & 25 \\
\hline${ }^{13} \mathrm{C}_{12}-1,2,3,4,6,7,8-\mathrm{Cl}_{7} \mathrm{DD}$ & 25 & 25 & 25 & 25 & 25 & 25 \\
\hline${ }^{13} \mathrm{C}_{12} \mathrm{Cl}_{8} \mathrm{DD}$ & 50 & 50 & 50 & 50 & 50 & 50 \\
\hline \multicolumn{7}{|l|}{ Recovery standards } \\
\hline${ }^{13} \mathrm{C}_{12}-1,2,3,4-\mathrm{Cl}_{4} \mathrm{DD}$ & 10 & 10 & 10 & 10 & 10 & 10 \\
\hline${ }^{13} \mathrm{C}_{12}-1,2,3,7,8,9-\mathrm{Cl}_{6} \mathrm{DD}$ & 25 & 25 & 25 & 25 & 25 & 25 \\
\hline
\end{tabular}


The isotopically labeled PCDD standards, with isotopic purity greater than $99 \%$, were purchased from Cambridge Isotope Laboratory (CIL), Woburn, MA. These standards included ${ }^{13} \mathrm{C}_{12}-1,2,3,4-\mathrm{Cl}_{4} \mathrm{DD},{ }^{13} \mathrm{C}_{12}$ 2,3,7,8-Cl ${ }_{4} \mathrm{DD},{ }^{13} \mathrm{C}_{12}-1,2,3,7,8,-\mathrm{Cl}_{5} \mathrm{DD},{ }^{13} \mathrm{C}_{12}-1,2,3,6$, $7,8-\mathrm{Cl}_{6} \mathrm{DD},{ }^{13} \mathrm{C}_{12}-1,2,3,7,8,9-\mathrm{Cl}_{6} \mathrm{DD},{ }^{13} \mathrm{C}_{12}-1,2,3,4,6,7$, ${ }_{8}^{8} \mathrm{Cl}_{7} \mathrm{DD},{ }^{13} \mathrm{C}_{12}-1,2,3,4,6,7,8,9-\mathrm{Cl}_{8} \mathrm{DD}$, and ${ }^{13} \mathrm{C}_{12}-1-\mathrm{Br}-$ $2,3,7,8-\mathrm{Cl}_{4} \mathrm{DD}$. The five $\mathrm{BPCDD}$ standards were $2-\mathrm{Br}-$ 3,7,8-Cl ${ }_{3} \mathrm{DD}, \quad 2-\mathrm{Br}-1,3,7,8-\mathrm{Cl}_{4} \mathrm{DD}$, 2-Br-3,6,7,8,9$\mathrm{Cl}_{5} \mathrm{DD}, 1-\mathrm{Br}-2,3,6,7,8,9-\mathrm{Cl}_{6} \mathrm{DD}$, and $1-\mathrm{Br}-2,3,4,6,7,8$, $9-\mathrm{Cl}_{7} \mathrm{DD}$. These compounds were synthesized by Radian Corporation, and purchased from CIL. Calibration standard solutions (CS1-CS6) as well as a standard solution containing a mixture of internal standards were made by serial dilution with tridecane as the solvent. The concentrations of these standard solutions are listed in Table 1.

\section{Sample Extraction and Cleanup}

Samples were extracted and the extracts were cleaned up in accord with the USEPA guidelines for the analysis of PCDDs; detailed descriptions were reported elsewhere $[27,28]$. Briefly, after spiking ${ }^{13} \mathrm{C}$-labeled PCDD internal standards into samples, dioxins were solvent extracted by using a Soxhlet apparatus, and the extract was submitted to an acid/base wash and fractionated by using a multicolumn liquid chromatographic technique prior to GC/MS analysis. The same fractions containing PCDDs were used for the analysis of BPCDDs, and the recoveries were in the range of $70 \%$ to $90 \%$.

\section{HRGC/HRMS Analysis}

Gas chromatography. The high-resolution gas chromatograph was a Hewlett-Packard (Palo Alto, CA) model 5890 operated in the splitless injection mode. Both the splitless injector port and direct GC/MS interface were heated to $275^{\circ} \mathrm{C}$. Two GC columns, DB-5 (60 $\mathrm{m} \times 0.32 \mathrm{~mm}$ i.d.) and DB-DIOXIN (60 $\mathrm{m} \times$ $0.25 \mathrm{~mm}$ i.d.), were purchased from J \& W Scientific (Folsom, CA). For the DB-5 column, helium was the carrier gas at a head pressure of $20 \mathrm{psi}$, resulting in a linear velocity of $\sim 35 \mathrm{~cm} \mathrm{~s}^{-1}$, and the oven temperature was programmed from $200^{\circ} \mathrm{C}(2 \mathrm{~min})$ to $220^{\circ} \mathrm{C}$ (16 min) at the rate of $5{ }^{\circ} \mathrm{C} \min ^{-1}$, then to $235^{\circ} \mathrm{C}(7$ $\left.\min , 5{ }^{\circ} \mathrm{C} \min ^{-1}\right)$, and finally to $330^{\circ} \mathrm{C}\left(5 \mathrm{~min}, 5^{\circ} \mathrm{C}\right.$ $\left.\min ^{-1}\right)$. Hydrogen was used as the carrier gas for the DB-DIOXIN column at a head pressure of 15 psi to obtain a linear velocity similar to that used with the DB-5 column. The GC oven was programmed from an initial temperature of $180-220^{\circ} \mathrm{C}$ at $10^{\circ} \mathrm{C} \mathrm{min}-1$ and held for $40 \mathrm{~min}$ when the DB-DIOXIN column was used.

Mass spectrometry. The high-resolution mass spectrometer used was a Kratos CONCEPT IS double- focusing sector instrument (Kratos Analytical Inc., Manchester, England). An EI source was used, and the ion source temperature was $250^{\circ} \mathrm{C}$. The flament current was $500 \mu \mathrm{A}$ in the trap stabilization mode with an electron energy between 30 and $40 \mathrm{eV}$. An electron multiplier at a gain of $\sim 10^{6}$, in combination with a postacceleration detector at $8 \mathrm{kV}$ was used for ion detection.

The methods of tuning the instrument for establishing consistent high resolution $(>10,000$ at $10 \%$ valley definition), as well as of selecting the lock masses for BPCDDs, were similar to the procedure for PCDDs, which was reported previously [28]. The masses monitored for BPCDDs are given in Table 2. High resolution selected ion monitoring was utilized with magnet switching among tetra through octa groups to achieve maximum sensitivity.

\section{Quantification of BPCDDs}

Initial calibration of the instrument for quantification of BPCDDS were performed by injecting the calibration standard solutions at six different levels covering the concentration range of interest. Relative response factors, which is the mass spectrometric response of a BPCDD compound of interest relative to a ${ }^{13} \mathrm{C}$ labeled PCDD internal standard of the same congener group, were calculated by the formula: $\operatorname{RRF}=\left(A_{x} \times\right.$ $\left.Q_{\text {is }}\right) /\left(A_{\text {is }} \times Q_{\mathrm{x}}\right)$, where $A_{\mathrm{x}} \equiv$ integrated areas of two quantification ion abundances of a BPCDD congener; $Q_{\text {is }} \equiv$ quantity of the internal standard in the solution (pg); $A_{\text {is }}=$ integrated areas of two quantification ion abundances of the internal standard; $Q_{\mathrm{x}} \equiv$ quantity of a BPCDD congener in the solution (pg). The mean relative response factors, $\overline{R R F}$, of a BPCDD congener were obtained by averaging the RRFs measured from injections at six levels, and these factors were then used for quantification of BPCDDs.

The concentrations of BPCDD compounds were calculated by using the equation: $C_{\mathrm{x}}=\left(A_{\mathrm{x}} \times\right.$ $\left.Q_{\text {is }}\right) /\left(A_{\text {is }} \times W_{\text {sample }} \times \overline{R R F}\right)$ where $C_{x} \equiv$ concentration $(\mathrm{pg} / \mathrm{g})$ of a BPCDD congener or several coeluting isomers in a gas chromatographic peak; $A_{\mathrm{x}} \equiv$ integrated areas of two quantitation ion abundances of BPCDDs; $Q_{\text {is }} \equiv$ quantity (pg) of the PCDD internal standard spiked into the sample prior to extraction, $A_{\text {is }} \equiv$ integrated areas of two quantitation ion abundances of the internal standard; $W_{\text {sample }} \equiv$ weight (g) of the sample, and $\overline{\mathrm{RRF}} \equiv$ mean relative response factor of a BPCDD congener obtained in the initial calibration.

\section{Results and Discussion}

\section{Mass Spectrometry}

Several studies have revealed that molecular ions are the most abundant ions upon electron ionization of BPCDDs $[6-10,15]$. As a result, monitoring the 
Table 2. Ions monitored for determination of BPCDDs

\begin{tabular}{|c|c|c|c|c|}
\hline Group & Mass & Ion & $\begin{array}{l}\text { Elemental } \\
\text { composition }\end{array}$ & Analyte \\
\hline \multirow[t]{6}{*}{1} & 331.9368 & $M$ & ${ }^{13} \mathrm{C}_{12} \mathrm{H}_{4}{ }^{35} \mathrm{Cl}_{4} \mathrm{O}_{2}$ & $\mathrm{Cl}_{4} \mathrm{DD}(\mathrm{s})^{\mathrm{a}}$ \\
\hline & 333.9339 & $M+2$ & ${ }^{13} \mathrm{C}_{12} \mathrm{H}_{4}{ }^{35} \mathrm{Cl}_{3}{ }^{37} \mathrm{ClO}_{2}$ & $\mathrm{Cl}_{4} \mathrm{DD}(\mathrm{s})$ \\
\hline & 365.8436 & $M+2$ & $\mathrm{C}_{12} \mathrm{H}_{4}{ }^{35} \mathrm{Cl}_{2}{ }^{37} \mathrm{Cl}^{79} \mathrm{BrO}_{2}$ & $\mathrm{BrCl}_{3} \mathrm{DD}$ \\
\hline & 367.8407 & $M+4$ & $\begin{array}{l}\mathrm{C}_{12} \mathrm{H}_{4}{ }^{35} \mathrm{Cl}^{37} \mathrm{Cl}_{2}{ }^{79} \mathrm{BrO}_{2} \\
\mathrm{C}_{12} \mathrm{H}_{4}{ }^{35} \mathrm{Cl}_{2}{ }^{37} \mathrm{Cl}^{91} \mathrm{BrO}_{2}\end{array}$ & $\mathrm{BrCl}_{3} \mathrm{DD}$ \\
\hline & 342.9790 & Lock & $\mathrm{C}_{8} \mathrm{~F}_{13}$ & PFK \\
\hline & 380.9758 & $a c^{b}$ & $\mathrm{C}_{8} \mathrm{~F}_{15}$ & PFK \\
\hline \multirow[t]{6}{*}{2} & 367.8949 & $M+2$ & ${ }^{13} \mathrm{C}_{12} \mathrm{H}_{3}{ }^{35} \mathrm{Cl}_{4}{ }^{37} \mathrm{ClO}_{2}$ & $\mathrm{Cl}_{5} \mathrm{DD}(\mathrm{s})$ \\
\hline & 369.8919 & $M+4$ & ${ }^{13} \mathrm{C}_{12} \mathrm{H}_{3}{ }^{35} \mathrm{Cl}_{3}{ }^{37} \mathrm{Cl}_{2} \mathrm{O}_{2}$ & $\mathrm{Cl}_{5} \mathrm{DD}(\mathrm{s})$ \\
\hline & 401.8017 & $M+4$ & $\begin{array}{l}\mathrm{C}_{12} \mathrm{H}_{3}{ }^{35} \mathrm{Cl}_{2}{ }^{37} \mathrm{Cl}_{2}{ }^{79} \mathrm{BrO}_{2} \\
\mathrm{C}_{12} \mathrm{H}_{3}{ }^{35} \mathrm{Cl}_{3}{ }^{37} \mathrm{Cl}_{1}{ }^{81} \mathrm{BrO}_{2}\end{array}$ & $\mathrm{BrCl}_{4} \mathrm{DD}$ \\
\hline & 403.7987 & $M+6$ & $\begin{array}{l}\mathrm{C}_{12} \mathrm{H}_{3}{ }^{35} \mathrm{Cl}^{37} \mathrm{Cl}_{3}{ }^{79} \mathrm{BrO}_{2} \\
\mathrm{C}_{12} \mathrm{H}_{3}{ }^{35} \mathrm{Cl}_{2}{ }^{37} \mathrm{Cl}_{2}{ }^{81} \mathrm{BrO}_{2}\end{array}$ & $\mathrm{BrCl}_{4} \mathrm{DD}$ \\
\hline & 380.9758 & Lock & $\mathrm{C}_{8} \mathrm{~F}_{13}$ & PFK \\
\hline & 416.9758 & $\mathbf{Q C}$ & $\mathrm{C}_{13} \mathrm{~F}_{16}$ & PFK \\
\hline \multirow[t]{6}{*}{3} & 401.8559 & $M+2$ & ${ }^{13} \mathrm{C}_{12} \mathrm{H}_{2}{ }^{35} \mathrm{Cl}_{5}{ }^{37} \mathrm{ClO}_{2}$ & $\mathrm{Cl}_{6} \mathrm{DD}\{\mathrm{s}\}$ \\
\hline & 403.8529 & $M+4$ & ${ }^{13} \mathrm{C}_{12} \mathrm{H}_{2}{ }^{35} \mathrm{Cl}_{4}{ }^{37} \mathrm{Cl}_{2} \mathrm{O}_{2}$ & $\mathrm{Cl}_{6} \mathrm{DO}(\mathrm{s})$ \\
\hline & 435.7627 & $M+4$ & $\begin{array}{l}\mathrm{C}_{12} \mathrm{H}_{2}{ }^{35} \mathrm{Cl}_{3}{ }^{37} \mathrm{Cl}_{2}{ }^{79} \mathrm{BrO}_{2} \\
\mathrm{C}_{12} \mathrm{H}_{2}{ }^{35} \mathrm{Cl}_{4}{ }^{37} \mathrm{Cl}^{81} \mathrm{BrO}_{2}\end{array}$ & $\mathrm{BrCl}_{5} \mathrm{DD}$ \\
\hline & 437.7598 & $M+6$ & $\begin{array}{l}\mathrm{C}_{12} \mathrm{H}_{2}{ }^{35} \mathrm{Cl}_{2}{ }^{37} \mathrm{Cl}_{3}{ }^{79} \mathrm{BrO}_{2} \\
\mathrm{Cl}_{12} \mathrm{H}_{2}{ }^{35} \mathrm{Cl}_{3}{ }^{37} \mathrm{Cl}_{2}{ }^{81} \mathrm{BrO}_{2}\end{array}$ & $\mathrm{BrCl}_{5} \mathrm{DD}$ \\
\hline & 430.9726 & Lock & $\mathrm{C}_{9} \mathrm{~F}_{17}$ & PFK \\
\hline & 442.9726 & $\mathrm{OC}$ & $\mathrm{C}_{10} \mathrm{~F}_{17}$ & PFK \\
\hline \multirow[t]{6}{*}{4} & 435.8169 & $M+2$ & ${ }^{13} \mathrm{C}_{12} \mathrm{H}^{35} \mathrm{Cl}_{6}{ }^{37} \mathrm{ClO}_{2}$ & $\mathrm{Cl}_{7} \mathrm{DD}(\mathrm{s})$ \\
\hline & 437.8140 & $M+4$ & ${ }^{13} \mathrm{C}_{12} \mathrm{H}^{35} \mathrm{Cl}_{5}{ }^{37} \mathrm{Cl}_{2} \mathrm{O}_{2}$ & $\mathrm{Cl}_{7} \mathrm{DD}(\mathrm{s})$ \\
\hline & 469.7238 & $M+4$ & $\begin{array}{l}\mathrm{C}_{12} \mathrm{H}^{36} \mathrm{Cl}_{4}{ }^{37} \mathrm{Cl}_{2}{ }^{79} \mathrm{BrO}_{2} \\
\mathrm{C}_{12} \mathrm{H}^{36} \mathrm{Cl}_{5}{ }^{37} \mathrm{Cl}^{81} \mathrm{BrO}_{2}\end{array}$ & $\mathrm{BrCl}_{6} \mathrm{DD}$ \\
\hline & 471.7280 & $M+6$ & $\begin{array}{l}\mathrm{C}_{12} \mathrm{H}^{35} \mathrm{Cl}_{3}{ }^{37} \mathrm{Cl}_{3}{ }^{79} \mathrm{BrO}_{2} \\
\mathrm{C}_{12} \mathrm{H}^{36} \mathrm{Cl}_{4}{ }^{37} \mathrm{Cl}_{2}{ }^{81} \mathrm{BrO}_{2}\end{array}$ & $\mathrm{BrCl}_{6} \mathrm{DD}$ \\
\hline & 442.9726 & Lock & $\mathrm{C}_{10} \mathrm{~F}_{17}$ & PFK \\
\hline & 442.9726 & $\mathrm{OC}$ & $\mathrm{C}_{10} \mathrm{~F}_{17}$ & PFK \\
\hline \multirow[t]{6}{*}{5} & 469.7780 & $M+2$ & ${ }^{13} \mathrm{C}_{12}{ }^{35} \mathrm{Cl}_{7}{ }^{37} \mathrm{ClO}_{2}$ & $\mathrm{Cl}_{8} \mathrm{DD}(\mathrm{s})$ \\
\hline & 471.7750 & $M+4$ & ${ }^{13} \mathrm{C}_{12}{ }^{35} \mathrm{Cl}_{6}{ }^{37} \mathrm{Cl}_{2} \mathrm{O}_{2}$ & $\mathrm{Cl}_{8} \mathrm{DD}(\mathrm{s})$ \\
\hline & 503.6848 & $M+4$ & $\begin{array}{l}\mathrm{C}_{12}{ }^{35} \mathrm{Cl}_{5}{ }^{37} \mathrm{Cl}_{2}{ }^{79} \mathrm{BHO}_{2} \\
\mathrm{C}_{12}{ }^{35} \mathrm{Cl}_{6}{ }^{37} \mathrm{Cl}^{81} \mathrm{BrO}_{2}\end{array}$ & $\mathrm{BrCl}_{7} \mathrm{DD}$ \\
\hline & 505.6818 & $M+6$ & $\begin{array}{l}\mathrm{C}_{12}{ }^{35} \mathrm{Cl}_{4}{ }^{37} \mathrm{Cl}_{3}{ }^{79} \mathrm{BrO}_{2} \\
\mathrm{C}_{12}{ }^{35} \mathrm{Cl}_{5}{ }^{37} \mathrm{Cl}_{2}{ }^{81} \mathrm{BrO}_{2}\end{array}$ & $\mathrm{BrCl}_{7} \mathrm{DD}$ \\
\hline & 480.9695 & Lock & $\mathrm{C}_{10} \mathrm{~F}_{19}$ & PFK \\
\hline & 516.9695 & $\mathrm{OC}$ & $\mathrm{C}_{13} \mathrm{~F}_{19}$ & PFK \\
\hline
\end{tabular}

molecular ions is the method of choice to achieve high sensitivity and specificity. We did not, however, always monitor the most abundant ions such as $\mathrm{M}^{+}$, $[\mathrm{M}+2]^{+}$, or $[\mathrm{M}+4]^{+}$for BPCDDs owing to possible interfering ions from polyhalogenated aromatic hydrocarbons (PHAH); these interferences were discussed previously [16]. The $[\mathrm{M}+2]^{+}$and $[\mathrm{M}+4]^{+}$ ions were monitored for tetra-BPCDD congeners, and
$[\mathrm{M}+4]^{+}$and $[\mathrm{M}+6]^{+}$ions were chosen for penta through octa BPCDD groups to minimize possible interferences (see Table 2 for masses monitored). When both bromine and chlorine are present in a molecule such as $\mathrm{BPCDD},{ }^{37} \mathrm{Cl}$ or ${ }^{81} \mathrm{Br}$ substitution results in two similar masses in the molecular ion isotope cluster, which are not resolvable at 10,000 mass resolution. Therefore, the masses of $[M+2]^{+}$, 
Table 3. Observed isotope ratios by high resolution selected ion monitoring method for determination of BPCDDs at different concentration levels

\begin{tabular}{|c|c|c|c|c|c|c|c|c|c|c|}
\hline \multirow[b]{2}{*}{ Compound } & \multicolumn{6}{|c|}{ Observed isotope ratios (OIR) } & \multirow[b]{2}{*}{ Mean OIR } & \multirow{2}{*}{$\begin{array}{c}\text { RSD }^{a} \\
(\%)\end{array}$} & \multirow[b]{2}{*}{$T I R^{b}$} & \multirow{2}{*}{$\begin{array}{l}\text { RD }^{c} \\
(\%)\end{array}$} \\
\hline & CS1 & $\operatorname{cs} 2$ & $\operatorname{cs3}$ & CS4 & CS5 & CS6 & & & & \\
\hline $2-\mathrm{Br}-3,7,8-\mathrm{Cl}_{3} \mathrm{DD}$ & 1.43 & 1.60 & 1.63 & 1.65 & 1.70 & 1.65 & 1.61 & 6.1 & 1.54 & 4.5 \\
\hline $2-\mathrm{Br}-1,3,7,8-\mathrm{Cl}_{4} \mathrm{DD}$ & 2.44 & 2.72 & 2.71 & 2.61 & 2.66 & 2.54 & 2.61 & 3.8 & 2.52 & 3.6 \\
\hline $2-\mathrm{Br}-3,6,7,8,9-\mathrm{Cl}_{5} \mathrm{DD}$ & 2.16 & 2.16 & 2.02 & 2.03 & 2.07 & 2.07 & 2.09 & 2.9 & 1.93 & 8.3 \\
\hline $1-\mathrm{Br}-2,3,6,7,8,9-\mathrm{Cl}_{6} \mathrm{DD}$ & 1.56 & 1.79 & 1.74 & 1.74 & 1.73 & 1.73 & 1.72 & 4.6 & 1.57 & 9.6 \\
\hline $1-\mathrm{Br}-2,3,4,6,7,8,9-\mathrm{Cl}_{7} \mathrm{DD}$ & 1.29 & 1.36 & 1.35 & 1.41 & 1.25 & 1.41 & 1.35 & 4.8 & 1.32 & 2.3 \\
\hline
\end{tabular}

Relative standard deviation

Theoretical isotope ratio for the pair ions monitored.

Relative deviation of mean values of QIR from TIR.

$[M+4]^{+}$, or $[M+6]^{+}$ions shown in Table 2 for BPCDDs are an average of the two masses: one containing ${ }^{37} \mathrm{Cl}$ and the other containing ${ }^{81} \mathrm{Br}$.

The isotope ratio of the two ions monitored is an important criterion for identifying trace BPCDDs. Observed isotope ratios (OIRs) for BPCDD calibration solutions at various concentration levels are given in Table 3. The relative standard deviations (RSDs) of OIRs for tetracongeners through octacongeners are only a few percent, showing excellent reproducibility of the method for isotope ratio measurement. The mean values of OIRs deviated $< \pm 10 \%$ from theoretical isotope ratios for all BPCDD groups. This good agreement between observed isotope ratio and theoretical isotope ratio serves as a demonstration that the instrumentation was able to measure the isotope ratio of BPCDDs with good accuracy and precision, which added to the certainty of the analytical method for BPCDDs in complex matrices.

The method used for determination of BPCDDs is an internal standard method whereby known amounts of isotopically labeled internal standards are added prior to sample preparation. The quantification of BPCDDs in samples is based on the amount and the response of the PCDD isotopically labeled standard for a specific BPCDD congener. Consequently, the mass spectrometric responses of BPCDDs and their internal standards must be found by measuring the RRFs in an initial mass spectrometric calibration. The results are given in Table 4. The mean values of RRFs ranged from 0.2 to 0.6 for BPCDDs, as compared to
RRFs of close to unity for PCDDs [28]. These low RRF values for BPCDDs determined in this study indicate that, in previous investigations of BPCDDs in which PCDDs' $R$ RFs were used $[6,9,10,15,16]$, the levels of BPCDDS were underestimates. The departure of RRFs for BPCDDs from unity is due partly to the molecular weights of BPCDDs that are higher than those of PCDDs, so that fewer molecules of BPCDDs are actually introduced into a mass spectrometer when the same quantities of BPCDDs and PCDDs are injected into the GC.

Deviation of RRFs from unity, however, is not a problem in determination of BPCDDs as long as the values are reproducible. Reproducibility is demonstrated by the low RSDs obtained by multiple injections of calibration standards at the concentration range of interest. Typically, the RSDs, given in Table 4 , are $\sim 10 \%$ or less for low-picogram to low-nanogram concentrations of BPCDDs when concentrations of internal standards were at fixed concentrations (see Table 1). Such small variation in RRF values over a large concentration range is evidence that BPCDDs can be accurately quantified in these concentration ranges by using this method.

At the lowest concentration of the calibration solution CS1, $500 \mathrm{fg} / \mu \mathrm{L}$ for tetra-, $2.5 \mathrm{pg} / \mu \mathrm{L}$ for pentathrough hepta-, and $5.0 \mathrm{pg} / \mu \mathrm{L}$ for octa-BPCDDs, a signal-to-noise ratio of at least 10 was observed for all congeners when a $2-\mu \mathrm{L}$ solution was injected. This instrument sensitivity gives a method detection limit of low or sub-parts-per-trillion for BPCDDs if a typical

Table 4. Relative response factors of $B P C D D s$ to their internal standards of ${ }^{13} \mathrm{C}_{12}-\mathrm{PCCDs}$ computed in initial calibration

\begin{tabular}{lcccccccc}
\hline & \multicolumn{9}{c}{ Relative response factor (RRF) } & Mean & \multicolumn{2}{c}{ RSD } \\
Compound & CS1 $^{8}$ & CS2 & CS3 & CS4 & CS5 & CS6 & RRF & (\%) \\
\hline \hline $2-\mathrm{Br}-3,7,8-\mathrm{Cl}_{3} \mathrm{DD}$ & 0.2061 & 0.2264 & 0.1881 & 0.1908 & 0.1929 & 0.1817 & 0.1977 & 8.19 \\
$2-\mathrm{Br}-1,3,7,8-\mathrm{Cl}{ }_{4} \mathrm{DD}$ & 0.4843 & 0.5355 & 0.3975 & 0.4504 & 0.4683 & 0.4310 & 0.4611 & 10.26 \\
$2-\mathrm{Br}-3,6,7,8,9-\mathrm{Cl}{ }_{5} \mathrm{DD}$ & 0.6737 & 0.6827 & 0.5071 & 0.5643 & 0.5964 & 0.5528 & 0.5962 & 11.70 \\
$1-\mathrm{Br}-2,3,6,7,8,9-\mathrm{Cl}_{6} \mathrm{DD}$ & 0.6303 & 0.6464 & 0.5234 & 0.5743 & 0.5743 & 0.5432 & 0.5820 & 8.26 \\
$1-\mathrm{Br}-2,3,4,6,7,8,9-\mathrm{Cl}_{7} \mathrm{DD}$ & 0.2853 & 0.3157 & 0.2435 & 0.2825 & 0.2591 & 0.2717 & 0.2763 & 8.96 \\
\hline
\end{tabular}

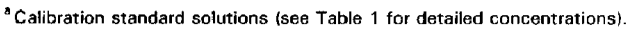


sample size is $10 \mathrm{~g}$ and a final sample extract volume is $10 \mu \mathrm{L}$ prior to taking an aliquot and injecting into the instrument.

One of the assumptions in this method of using isotopically labeled PCDDs as internal standards is that the BPCDD compounds have chemical properties similar to those of PCDDs, so that variations occurring in the sample preparation and GC/MS instrumental analysis can be compensated. There is evidence from previous studies $[6,9,10,15,16]$ that BPCDDs behave similarly to PCDDs in the sample preparation procedure. Similar instrument response for these two classes of compounds was demonstrated in this study by the linear calibration curves for BPCDDs as shown in Figure 1. Correlation coefficients of $0.9988,0.9980,0.9984,0.9990$, and 0.9992 were obtained for 2-Br-3,7,8-Cl $\mathrm{DD}, 2-\mathrm{Br}-1,3,7,8-$ $\mathrm{Cl}_{4} \mathrm{DD}, 2-\mathrm{Br}-3,6,7,8,9-\mathrm{Cl}_{5} \mathrm{DD}, 1-\mathrm{Br}-2,3,6,7,8,9-\mathrm{Cl}_{6} \mathrm{DD}$, and $1-\mathrm{Br}-2,3,4,6,7,8,9-\mathrm{Cl}_{7} \mathrm{DD}$, respectively.

\section{Gas Chromatography}

Because there are 198 possible BPCDD compounds of tetra-substitutions through octa-substitutions, a maximum GC separation power is needed to separate these compounds. Two capillary columns, a $60-\mathrm{m}$ DB-5 and a 60-m DB-DIOXIN, were demonstrated to give the best separation of PCDDs in earlier studies
$[22,23,28]$, and thus they were also employed for the analysis of BPCDDs.

The mass chromatograms for a standard of 2-Br$3,7,8-\mathrm{Cl}_{13} \mathrm{DD}$ (Figure $2 \mathrm{a}$ and $\mathrm{b}$ ) as well as for tetraBPCDDs of a fly ash sample (Figure $2 c$ and $d$ ), acquired in two separate runs with a 60 -m-long DB-5 column show the complexity of the fly ash sample. On the basis of the retention time of the standard, $2-\mathrm{Br}-3,7,8-\mathrm{Cl}_{3} \mathrm{DD}$ was identified to correspond to a shoulder of the largest peak in the retention window, as marked at approximately 25:30 (Figure $2 \mathrm{c}$ and d). This compound is of particular interest because its counterpart, $2,3,7,8-\mathrm{Cl}_{4} \mathrm{DD}$, has the dubious distinction of being "the most toxic man-made chemical" [4, 5]. Although 2,3,7,8- $\mathrm{Cl}_{4} \mathrm{DD}$ can be separated with this column under identical conditions [28], the column apparently does not have enough efficiency to separate $2-\mathrm{Br}-3,7,8-\mathrm{Cl}_{3} \mathrm{DD}$ from other tetra-BPCDDs, simply because there are many more tetra-BPCDD isomers (possible total 70 ), as compared to only 22 tetra-PCDDs.

The mass chromatograms acquired with a 60 m-long DB-DIOXIN column show that separation of tetra-BPCDDs can be improved (Figure 3 ). The compound of interest, $2-\mathrm{Br}-3,7,8-\mathrm{Cl}_{3} \mathrm{DD}$ (Figure $3 \mathrm{c}$ and $\mathrm{d}$ ) appeared as an observable chromatographic peak at the retention time of 45:05 min, which agrees with that of the standard compound determined in a sepa-

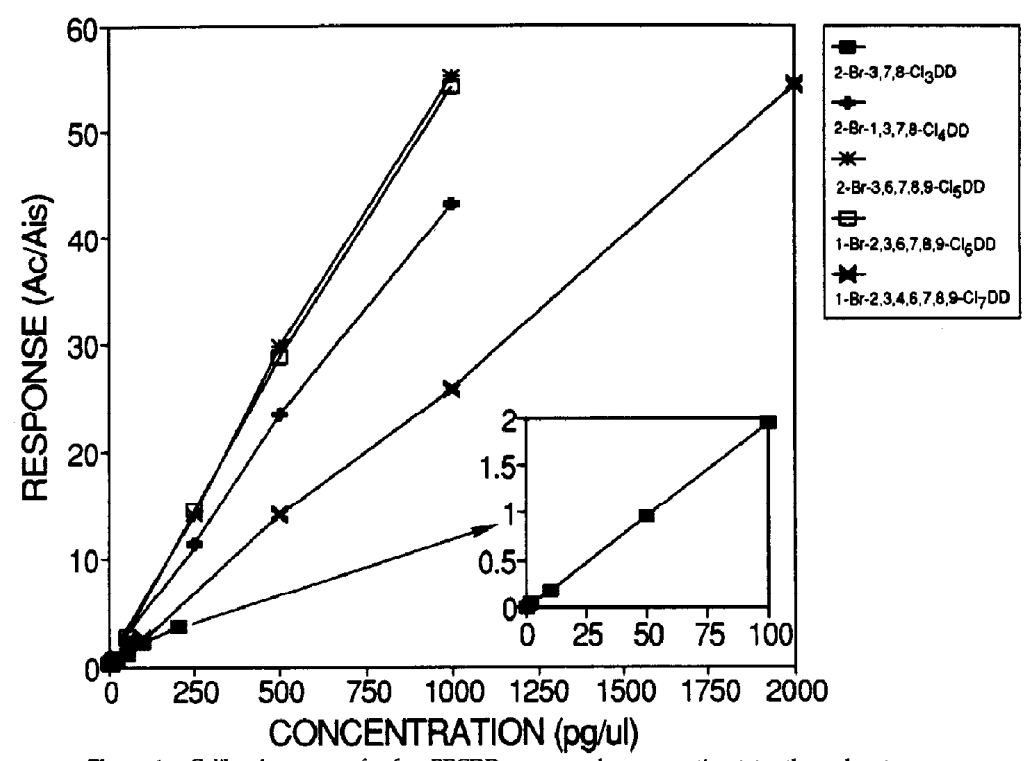

Figure 1. Calibration curves for five BPCDD compounds representing tetra through octa groups. The response (area of the compound/area of internal standard) is plotted against concentration of BPCDD standards in calibration standard solutions (CS1-CS6; see Table 1 for detailed concentrations). 
Figure 2. Mass chromatograms of (a) $[\mathrm{M}+2]^{+}$and (b) $[\mathrm{M}+4]^{+}$ions of the standard compound of 2-Br-3,7,8-Cl $\mathrm{DD}$, and (c) $[\mathrm{M}+2]^{+}$and (d) $[\mathrm{M}+4]^{+}$ions of tetra BPCDDs detected in a fly ash sample acquired with a $60-\mathrm{m}-\mathrm{long}$ DB-5 GC column.

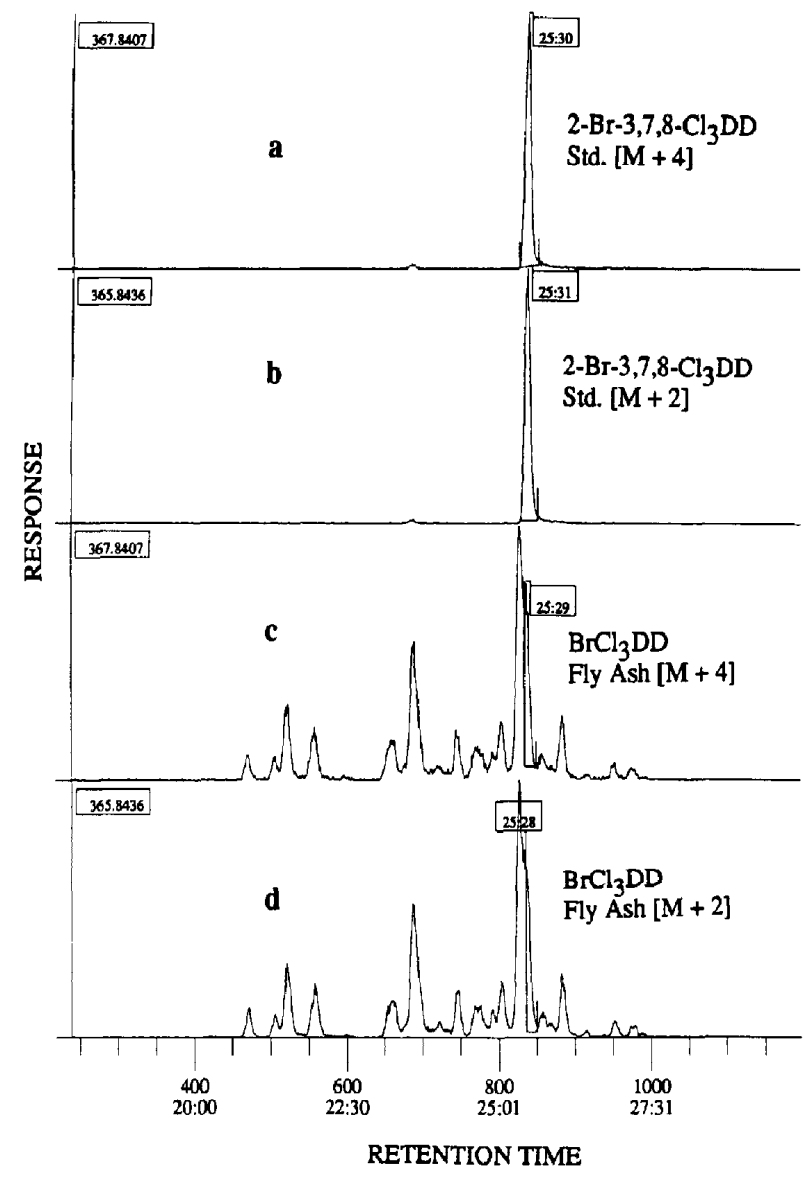

rate run (Figure 3a and b). This peak, however, may correspond to other coeluted tetra-BPCDDs, and an absolute isomer identification must await the synthesis and analysis of all 70 isomers of tetra-BPCDDs. It is interesting to note that even by using the $\mathrm{DB}$ DIOXIN column, the number of observed peaks of tetra-BPCDDs is considerably less than the theoretically expected 70 total possible, which agrees with the results of a previous finding in which a DB-5 column was used [16].

An attempt was also made to identify isomers in other congener groups by using the DB-5 column. The two important 2,3,7,8-substituted penta-BPCDDs, 1- $\mathrm{Br}-2,3,7,8-\mathrm{Cl}_{4} \mathrm{DD}$ and $2-\mathrm{Br}-1,3,7,8-\mathrm{Cl}_{4} \mathrm{DD}$, were found to elute at $34: 54$ and $35: 16 \mathrm{~min}$, respectively (Figure $4 \mathrm{e}$ and $\mathrm{f}$ ), as is verified by the retention times of standard compounds ${ }^{13} \mathrm{C}_{12}-1-\mathrm{Br}-2,3,7,8-\mathrm{Cl}{ }_{4} \mathrm{DD}$ (Figure $4 \mathrm{a}$ and $\mathrm{b}$ ) and $2-\mathrm{Br}-1,3,7,8-\mathrm{Cl}_{4} \mathrm{DD}$ (Figure $4 \mathrm{c}$ and d). Again, only partial separation was achieved. For hexacongeners and heptacongeners, the number of BPCDD isomers is fewer than those possible for tetracongeners and pentacongeners. Peaks at 41:17 min (Figure 5e and f) and at 45:54 min (Figure $5 \mathrm{c}$ and d) are identified as due to $2-\mathrm{Br}-3,6,7,8,9-\mathrm{Cl}_{5} \mathrm{DD}$, and 1$\mathrm{Br}-2,3,6,7,8,9-\mathrm{Cl}_{6} \mathrm{DD}$, respectively. It should be emphasized that all these isomer identifications are preliminary because the extent of coelution is not yet known. Further isomer specific determination of BPCDDs awaits future improvement in capillary columns and chromatographic techniques. We can, however, identify the two octa-BPCDD isomers, 1-Br$2,3,4,6,7,8,9-\mathrm{Cl}_{7} \mathrm{DD}$ and $2-\mathrm{Br}-1,3,4,6,7,8,9-\mathrm{Cl}_{7} \mathrm{DD}$, at 49:28 and 49:39 min, respectively, because the only two isomers in this group are well separated under the GC conditions employed here (see Figure $5 a$ and b). 


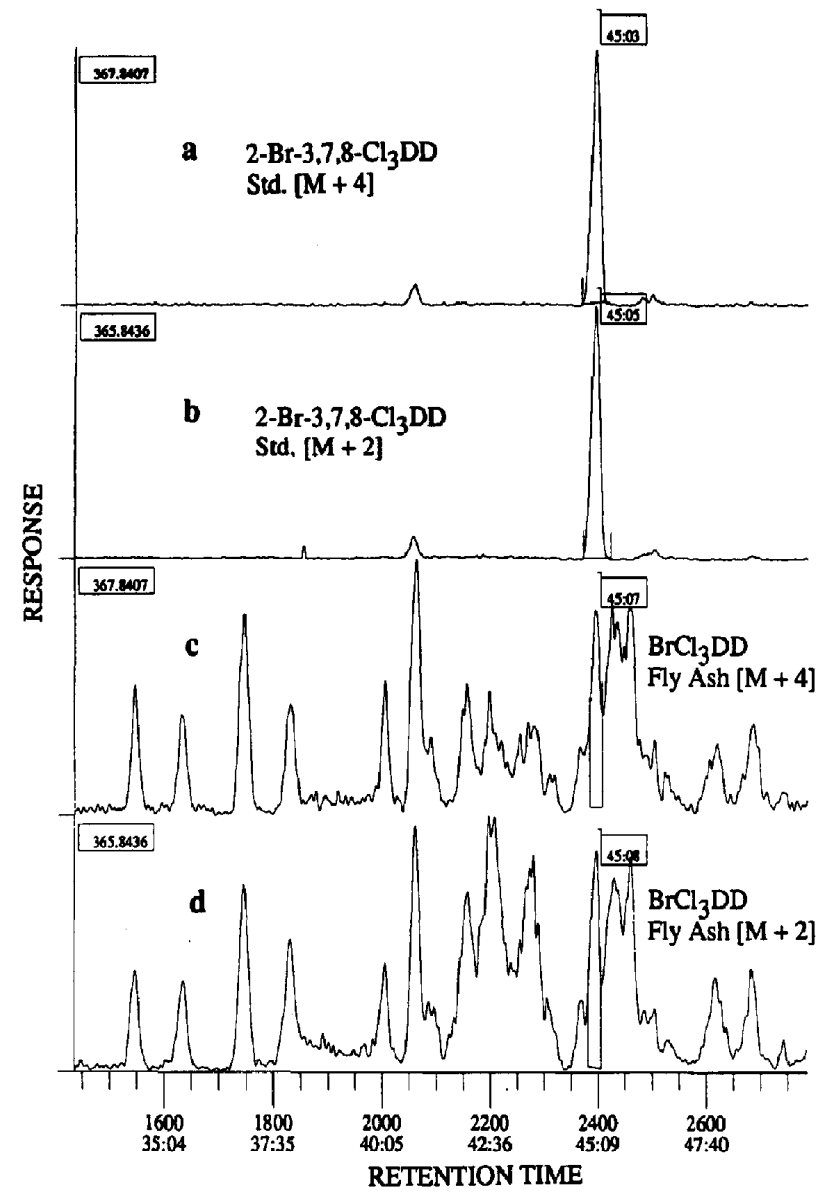

Figure 3. Mass chromatograms of (a) $[\mathrm{M}+2]^{+}$and (b) $[\mathrm{M}+4]^{+}$ions of the standard compound of 2- $\mathrm{Br}-3,7,8-\mathrm{Cl}_{3} \mathrm{DD}$, and (c) $[\mathrm{M}+2]^{+}$and (d) $[\mathrm{M}+4]^{+}$ions of tetra BPCDDs detected in a fly ash sample acquired with a 60-m-long DBDIOXIN GC Column.

\section{Validation of the Method}

A quantitative analytical method is usually validated by analyzing fortified samples, method blanks, and field samples. The repeated analyses of method blanks did not show detectable levels of BPCDDs.

Fortified samples of fish and fly ash were made by spiking BPCDD standards at different concentrations. The samples were then extracted and analyzed; the results are given in Table 5. For triplicate GC/MS injections, RSDs of $< \pm 10 \%$ were achieved for quantification of all BPCDD congeners, showing a satisfactory precision for the GC/MS analysis. The chromatographic traces of PFK ions monitored as the quality control ions for tetra through octa BPCDDs are illustrated in Figure 6, and excellent stability of mass spectrometric responses of these ions is observed during the monitored retention windows. Long-term stability of this HRMS instrument has been demonstrated for the analysis of PCDD/Fs (28), and it was found that reproducibility of relative mass spectrometric responses of BPCDDs to their isotopically labeled internal standards was within $\pm 15 \%$ over a period of a month. Method accuracy was assessed in terms of relative errors (REs), which are the differences between the observed values (detected) and the true values (spiked) divided by the true value [29]. The RE values (see Table 5) are $<20 \%$ for each BPCDD spiked, which means that the method accuracy of $>80 \%$ can be achieved.

Analyses of field samples such as fly ash from a municipal waste incinerator are usually much more 
complicated because hundreds to thousands of organic compounds coexist with BPCDDs. The criteria for identifying BPCDDs in such samples are (1) two exact masses of a congener at $>10,000$ mass resolution must be detected at the same retention time; (2) the observed isotope ratio of the two ions monitored must not deviate $> \pm 15 \%$ from theoretical isotope ratio; (3) the chromatographic peaks must show an elution within the defined windows for the congeners; (4) the relative retention times to the internal standards must be within $\pm 10 \%$ as measured in calibration runs; (5) the signal-to-noise-ratio of the peak must be $>2.5$.

Several fish samples were analyzed for BPCDDs, and none of them were found to contain detectable levels of BPCDDs. Fly ash samples collected from different countries were also analyzed for BPCDDs by this method, and substantial amounts of BPCDDs were detected in every sample. Data for three fly ash samples are given in Table 6 . The concentrations of total homologues of BPCDDs in these samples ranged from low parts-per-trillion to low parts-per-billion depending on the location where the sample was collected. The individual isomer concentrations in Table 6 are the maximum possible, again, because the degree of coelution of BPCDDs is not known at this time.

\section{Conclusions}

It has been shown that low or sub-parts-per-trillion levels of BPCDDs in fly ash from municipal waste incinerators can be quantifed by the capillary column GC/HRMS technique. This is yet another demonstration of the capabilities of a modern mass spectrometer

Figure 4. Mass chromatograms of (a) $[\mathrm{M}+4]^{+}$and $(\mathrm{b})[\mathrm{M}+6]^{+}$ions of ${ }^{13} \mathrm{C}_{12}$ $1-\mathrm{Br}-2,3,7,8-\mathrm{Cl}_{4} \mathrm{DD}$, (c) $[\mathrm{M}+4]^{+}$and (d) $[\mathrm{M}+6]^{+}$ions of $2-\mathrm{Br}-1,3,7,8-\mathrm{Cl}{ }_{4} \mathrm{DD}$, and (e) $[\mathrm{M}+4]^{+}$and $(f)[\mathrm{M}+6]^{+}$of penta. BPCDDs detected in a fly ash sample.

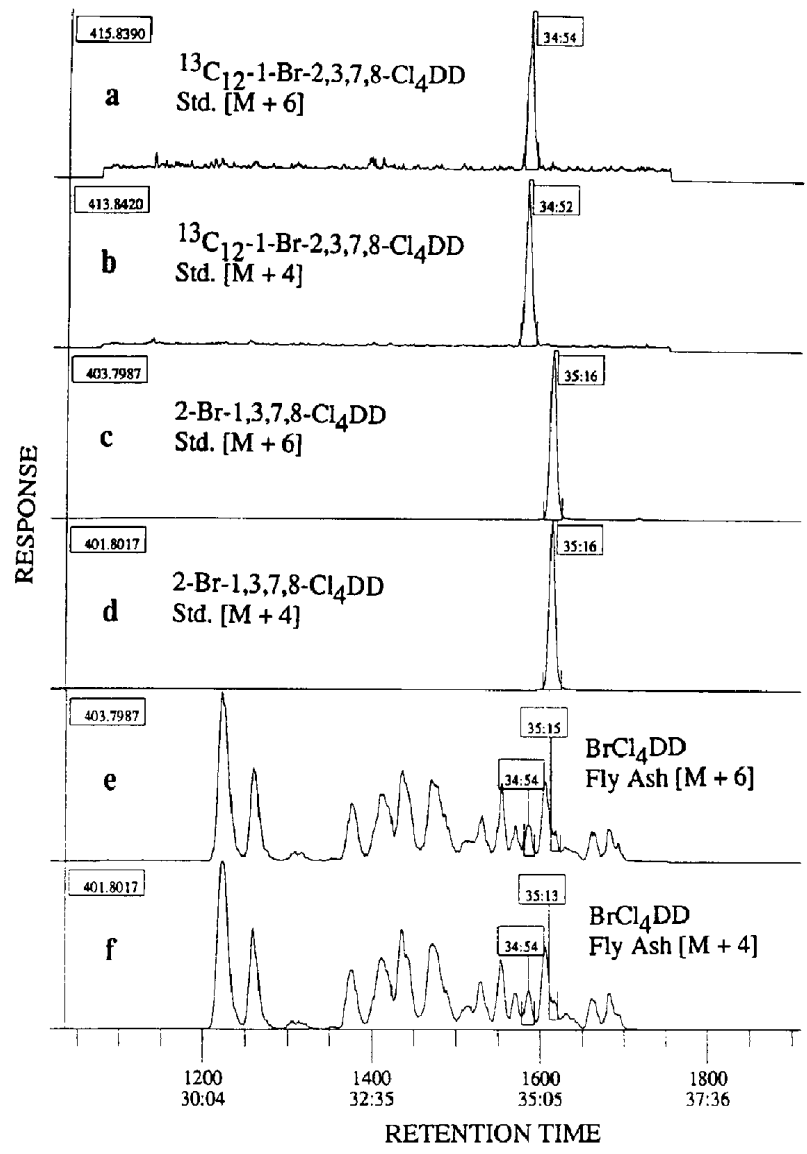


to preform a multicomponent analysis in a complex matrix with high sensitivity and specificity. Isomer specific determination of BPCDDs is, however, hampered by the limited GC separation power at this time. This situation should be ameliorated when better GC columns are developed and more BPCDD standards become available. Although utilization in this study of isotopically labeled PCDDs as internal standards for BPCDDs has resulted in linear calibration curves, the method accuracy and precision should also be improved once the whole range of isotopically labeled BPCDD standards are synthesized.

In another investigation [16], we also detected monobromopolychlorodibenzofurans (BPCDFs) in a fly ash sample. Simultaneous determination of
BPCDDs and BPCDFs, however, was not possible by the methods employed here because BPCDF standards were not available. The analysis for all $\mathrm{BPCDD} / \mathrm{Fs}$ is more challenging because not only are there many more isomers of BPCDFs, but also there are more possible overlaps in the chromatographic elution window between the $\mathrm{BPCDD} / \mathrm{Fs}$ and the PCDD/Fs.

\section{Acknowledgments}

Technical assistance of Anne Perron at the Connecticut Agricultural Experiment Station is greatly acknowledged. The Midwest Center for Mass Spectrometry was a National Science Foundation Regional Instrumentation Facility (grant no. CHE-8620177),

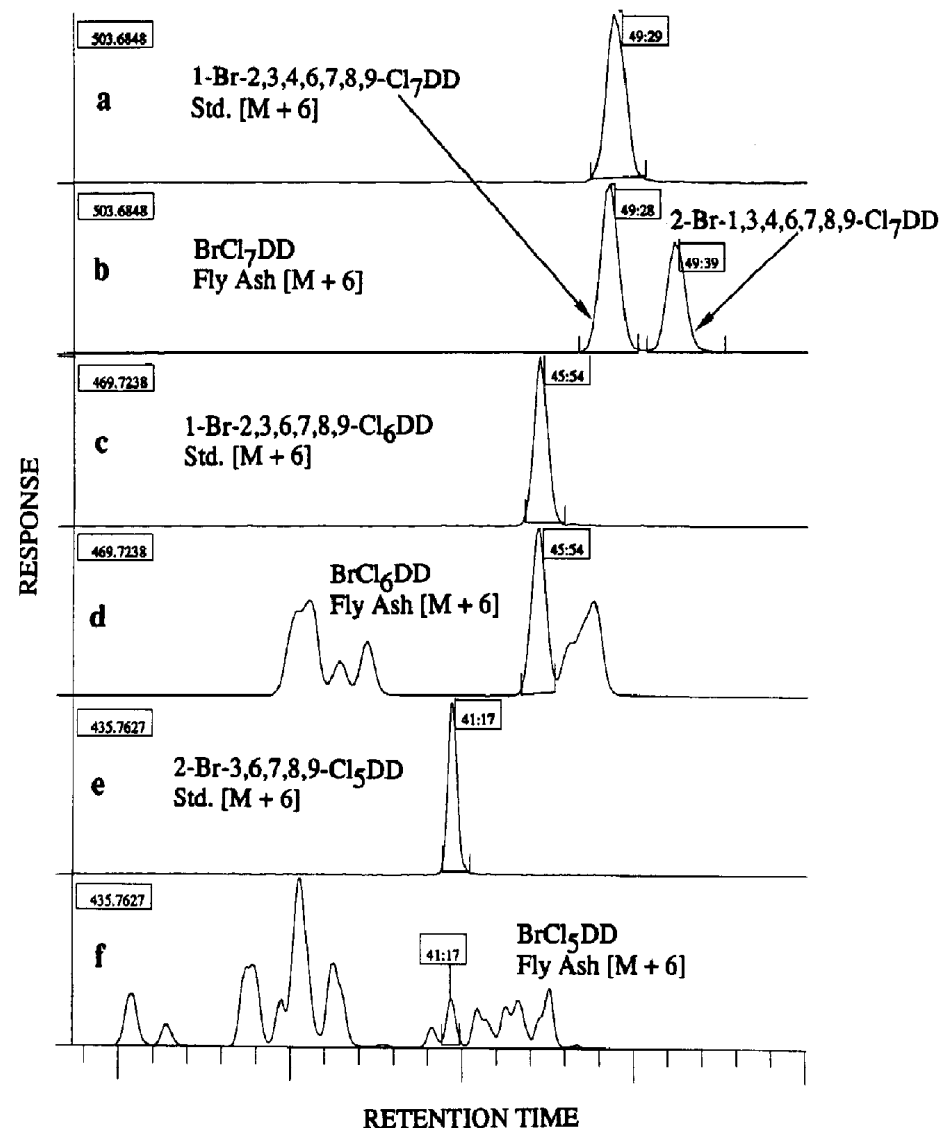

Figure 5. Mass chromatograms of (a) $[\mathrm{M}+6]^{+}$ion of $1-\mathrm{Br}-2,3,4,6,7,8,9-\mathrm{Cl}_{7} \mathrm{DD}$, (b) $[\mathrm{M}+6]^{+}$ion of Octa-BPCDDs detected in a fly ash sample; (c) $[\mathrm{M}+6]^{+}$ion of $1-\mathrm{Br}-2,3,6,7,8,9-\mathrm{Cl}_{6} \mathrm{DD}$, (d) $[\mathrm{M}+6]^{+}$ion of hepta BPCDDs detected in a fly ash sample; (e) $[\mathrm{M}+6]^{+}$ion of $2-\mathrm{Br}-3,6,7,8,9-$ $\mathrm{Cl}_{5} \mathrm{DD}$, and $(\mathrm{f})[\mathrm{M}+6]^{+}$ion of hexa BPCDDs detected in a fly ash sample. 


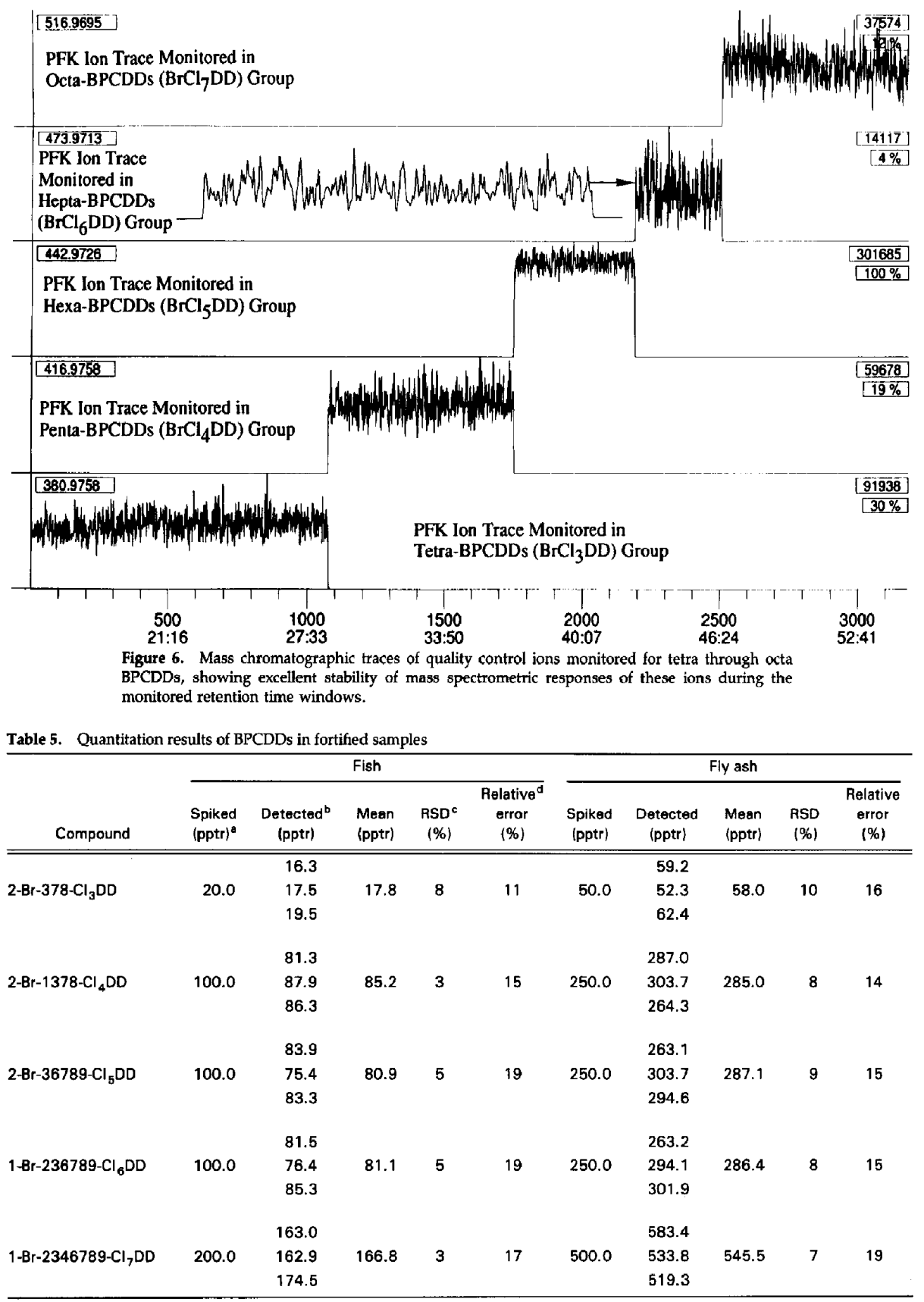

${ }^{a}$ Parts per trillion based on $10-\mathrm{g}$ sample.

Quantitation results from three GC/MS injections.

"Relative standard deviation of three replicate injections.

Relative error is defined as a difference between the observed value (detected) and the true value (spiked) divided by the true value. 
Table 6. Quantitation results of BPCDDs in municipal waste incinerator fly ash samples

\begin{tabular}{|c|c|c|c|}
\hline \multirow[b]{2}{*}{ Compound } & \multicolumn{3}{|c|}{ Concentrations $(\mathrm{pg} / \mathrm{g}, \mathrm{pptr})^{\mathrm{a}}$} \\
\hline & $\begin{array}{c}\text { Fly ash } 1 \\
\text { (country A) }\end{array}$ & $\begin{array}{l}\text { Fly ash } 4 \\
\text { (country B) }\end{array}$ & $\begin{array}{c}\text { Fly ash } 5 \\
\text { (country } \mathrm{C} \text { ) }\end{array}$ \\
\hline $2-\mathrm{Br}-3,7,8-\mathrm{Cl}_{3} \mathrm{DD}$ & 150.0 & 8.0 & 1565.0 \\
\hline Total $\mathrm{BrCl}_{3} \mathrm{DDs}$ & 2945.0 & 109.0 & 17415.0 \\
\hline $2-\mathrm{Br}-1,3,7,8-\mathrm{Cl}_{4} \mathrm{DD}$ & 13.0 & 0.4 & 398.0 \\
\hline Total $\mathrm{BrCl}_{4} \mathrm{DDs}$ & 2254.0 & 123.0 & 28891.0 \\
\hline $2-\mathrm{Br}-3,6,7,8,9-\mathrm{Cl}_{5} \mathrm{DD}$ & 113.0 & 3.0 & 1978.0 \\
\hline Total $\mathrm{BrCl}_{5} \mathrm{DDs}$ & 3930.0 & 164.0 & 38571.0 \\
\hline $1-\mathrm{Br}-2,3,6,7,8,9-\mathrm{Cl}_{6} \mathrm{DD}$ & 113.0 & 12.0 & 10223.0 \\
\hline Total $\mathrm{BrCl}_{6} \mathrm{DDs}$ & 3930.0 & 61.0 & 35308.0 \\
\hline $1-\mathrm{Br}-2,3,4,6,7,8,9-\mathrm{Cl}_{7} \mathrm{CDD}$ & 548.0 & 31.0 & 26271.0 \\
\hline Total $\mathrm{BrCl}_{7} \mathrm{DDs}$ & 2514.0 & 49.0 & 43158.0 \\
\hline
\end{tabular}

${ }^{a}$ Parts per trillion.

Partial support from National Science Foundation Biology Division is gratefully acknowledged (grant no. DIR-9017262).

\section{References}

1. Travis, C. C.; Hattemer-Frey, H. A.; Silbergeld, E. Environ. Sci. Technol. 1989, 23, 1061.

2. Hites, R. A. Acc. Chem. Res. 1990, 23, 194.

3. Health Assessment Document for Polychlorinated Dibenzo-pDioxins; EPA-600/8-84-014F; Environmental Protection Agency: Washington, DC, 1985.

4. Esposito, M. P.; Tiernan, T. V.; Dryden, F. E. In Dioxins; EPA-600/2-80-197; Environmental Protection Agency: Washington, DC, 1980.

5. Sparschu, G. L.; Dunn, F. L.; Rowe, F. L. Food Cosmet. Toxicol. 1971, 9, 405.

6. Buser, H. R. Chemosphere 1987, 16, 713.

7. Buser, H. R. Environ. Sci. Technol. 1986, 20, 404.

8. Buser, H. R. Anal. Chem. 1986, 58, 2913.

9. Donnelly, J. R.; Munslow, W. D.; Vonnahme, T. L.; Nunn, N. I.; Hedin, C. M.; Sovocool, G. W.; Mitchum, R. K. Biomed. Environ. Mass Spectrom. 1987, 14, 465.

10. Sovocool, G. W.; Mitchum, R. K.; Tondeur, Y.; Munslow, W. D.; Vonnahme, T. L.; Donnelly, J. R. Biomed. Environ. Mass Spectrom. 1988, 15, 669.

11. Thoma, H.; Rist, S.; Hauschulz, G.; Hutzinger, O. Chemosphere 1986, 15, 2111

12. Bauer, M. R.; Mitchum, R. K.; Munro, H. E.; Bonnilla, J. V. In Procedings of the 38th ASMS Conference, Tucson, $\mathrm{AZ}$, 1990; pp 665-666.

13. Kende, A. S.; Wade, J. J. Environ. Health Perspect. 1973, 5 , 49.

14. Ramaling, B; Mazer, T.; Wagel, D. J.; Mallow, C. M.; Taylor, M. L.; Tiernan, T. V.; Garrett, J. H.; Rifkind, A. B. In Chlorinated Dioxins and Dibenzofurans in Perspective; C.
Rappe; G. Choudhary; L. H. Keith, Eds.; Lewis Publishers: Chelsea, MI, 1986, p 485.

15. Schafer, W.; Ballschmiter, K. Chemosphere 1986, 15, 755.

16. Tong, H. Y.; Huang, L. Q.; Monson, S. J.; Gross, M. L. Annl. Chem., 1991, 63, 2697.

17. Thoma, H.; Hauschulz, G.; Hutzinger, O. Chemosphere 1987, $16,297$.

18. Thoma, H.; Hutzinger, O. Chemosphere 1987, 16, 1353.

19. Thoma, H.; Hauschulz, G.; Hutzinger, O. Chemosphere 1987, $16,1579$.

20. Tong, H. Y.; Gross, M. L. In Proceedings of the 36th ASMS Conference, San Francisco, CA, 1988; pp 230-231.

21. Tong, H. Y.; Monson, S. J.; Gross, M. L. In Proceedings of the 37th ASMS Conference, Miami Beach, FL, 1989; pp 1416-1417.

22. Tondeur, Y. USEPA Method 8290: Analytical Procedures and Quality Assurrance for Multimedia Analysis of Polychlorinated Dibenzo-p-Dioxins and Polychlorinated Dibenzofurans by HRGC/HRMS; Environmental Protection Agency: Washington, DC, June 1987.

23. USEPA Method 1613: Tetra- Through Octa-Chlorinated Dioxins and Furans by Isotope Dilution; Environmental Protection Agency: Washington, DC, July 1989.

24. Oehme, M.; Kirschmer, P. Anal. Chem. 1984, 56, 2754.

25. Miles, W. F.; Gurprasad, N. D.; Malis, G. P. Anal. Chem. 1985, 57, 1133.

26. Laramee, J. A.; Arbogast, B. C.; Deinzer, M. L. Anal. Chem. 1986, 58, 2907.

27. Tong, H. Y.; Arghestani, S.; Gross, M. L.; Karasek, F. W. Chemosphere 1989, 18, 577.

28. Huang, L. Q.; Eitzer, B.; Moore, C.; McGown, S.; Tomer, K. B. Biol. Mass Spectrom. 1991, 20, 161.

29. Fritz, J. S.; Schenk, G. H., Eds.; Quantitative Analytical Chemistry; Allyn and Bacon: Boston, 1979; p 25. 